\title{
Myotonic Dystrophy
}

National Cancer Institute

\section{Source}

National Cancer Institute. Myotonic Dystrophy. NCI Thesaurus. Code C84914.

An inherited progressive disorder affecting the muscles. It is characterized by muscle wasting and hypotonia, cataracts, heart conduction defects and endocrinopathies. 